\title{
obituaries
}

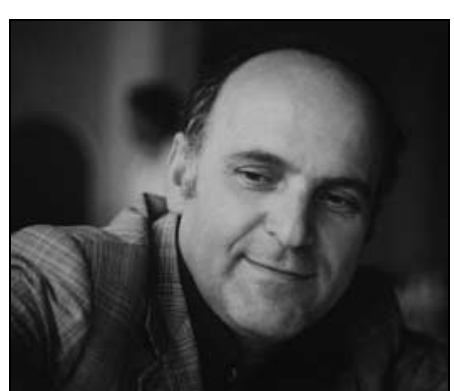

\section{Professor John Constantine Boulougouris}

Formerly Professor, Athens University, Greece, and a

Foundation Affiliate of the Royal College of Psychiatrists

John Boulougouris was a Greek psychiatrist who trained and worked at the Maudsley during the late 1960s. In England he was regarded by his contemporaries for his work and his likeable and charming personality. He was part of a group who developed clinical methods for the treatment of neurotic disorders including neurotic depression. He participated in several clinical studies and copublished influential articles on desensitisation and 'flooding' for phobias and obsessive-compulsive disorders.

John returned to Greece in 1973 and after fulfilling 1 year's compulsory service as a psychiatrist in the mental hospital in his native town, Tripoli, he was appointed senior lecturer at the Athens University Department of Psychiatry. He joined a team of two other senior lecturers, all British trained, and a newly appointed chairman, who all aspired to reform Greek psychiatry. This was the beginning of the modernisation of Greek psychiatry, which included developments in services, training and research.

The influence of the British school of psychiatry was paramount in Greece and John's role in it was decisive. In particular he brought into clinical practice systematic description of phenomenology and a new psychotherapeutic approach, which was not only psychodynamic psychotherapy, but the only one known and practised in Greece until then. John initiated several clinical studies in behaviour therapy and he became known as 'the behaviourist'. He was an inspiration to his students and trainees because of his clear thinking and his devotion to his patients.

John opted out from academia in the early 1980s and concentrated on his private practice, also spending an increasing amount of time in his country house in the Peloponnese. There he planted olive and fruit trees and grew large quantities of vegetables, which he enjoyed sending to his friends! John remained active in the world of behaviour therapy and was a member of several international organisations. He organised several international conferences in Greece and continued publishing widely. His latest contribution was the development of the Institute of Behaviour Therapy and Research in Athens, a non-profit centre for multi-disciplinary clinical service and training in methods of behaviour psychotherapy.

John Boulougouris leaves a distinct mark in contemporary Greek psychiatry as an innovator, a thinker and a pragmatist. His friends and colleagues will also always remember him for his humour, generosity and warm personality. He coped admirably with his sudden illness, but died because of a relapse of an inoperable condition. His wife Jenny, three sons and a grandson survive him.

\section{Nick Bouras}

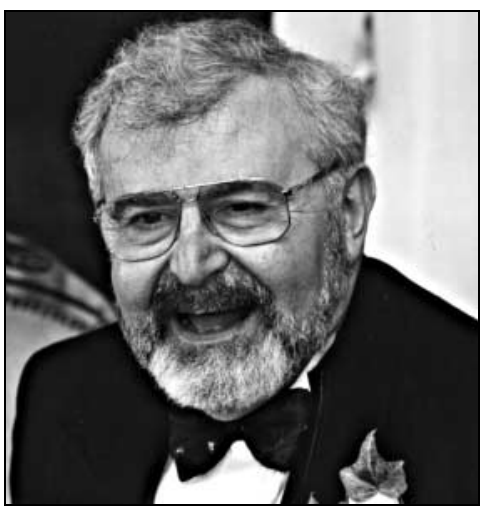

\section{Kenneth Lawrence Granville-Grossman}

Former Consultant Psychiatrist, St Mary's Hospital and Medical School, London

Kenneth, a distinguished and respected member of the staff at St Mary's, died suddenly, probably from cardiac dysrhythmia secondary to coronary atherosclerosis on 6 March 2000.

Born in London in 1929, he was educated at University College School and then University College Hospital Medical School. Postgraduate study led to the MD, FRCP and FRCPsych.

His undergraduate career was interrupted by a tuberculous pleural effusion in the days before the advent of chemotherapy. Fortunately, 4 months of enforced rest on a cold veranda was followed by a full recovery. He then managed to pick up three major prizes before qualifying in 1953.

He had always been interested in psychiatry and after his pre-registration posts he worked in the psychiatric observation ward at University College Hospital. The lack of effective treatment at that time appalled him and he returned to general medicine and obtained the MRCP. The arrival of chlorpromazine and imipramine reawakened his interest in psychiatry and he began his training at the Maudsley Hospital in 1960, progressing through the ranks from senior house officer to senior registrar. At this early stage he felt the need to experience a range of approaches to the subject and for some years undertook a training analysis. He finally came to the conclusion that a purely dynamic view was unsustainable and took a wider, more eclectic perspective.

He moved from the Maudsley to St Bartholomew's as a lecturer. There he did pioneering work on the use of betablockers in psychiatry.

His first consultant appointment was at Welwyn Garden City to open one of the first district general hospital psychiatric units to be built. In 1967 he was appointed to the staff at St Mary's. Here the more academic atmosphere spurred him to embark on the series Recent Advances in Clinical Psychiatry, for which he will be long remembered. The first edition, of which he was the sole author, appeared in 1971 and was an instant success. The series progressed to eight editions, of which he was the editor and a major contributor. Successive editions were required reading for a generation of aspirants for the MRCPsych.

Kenneth published widely in addition to the books. In the 1980s St Mary's was a major centre dealing with the burgeoning problem of AIDS and he provided the liaison service to the department of genitourinary medicine, developing an interest and expertise in the psychiatric problems associated with it. This led to further contributions to the literature.

He was a true 'scholar'. His natural habitat was the library and the study, but he did function at high level in other environments. He was one of the prime movers in expanding the role of psychiatry at St Mary's. When he arrived the department consisted of two very part-time consultants sharing seven in-patient beds on the general medical wards of the hospital. With colleagues he found funding for the creation of an academic department in the early 1970s and thereafter actively supported the massive expansion of psychiatric services to St Mary's and the local community.

At an early age he served on the Council of the College and then on the 
Court of Electors. For 11 years he was the Regional Adviser in Psychiatry to the North West Thames Region. For the Department of Health and Social Services he served on the Committee on the Review of Medicines from 1984 to 1986. One commitment he particularly enjoyed was as psychiatrist to the Crown Colony of Gibraltar from 1970 until his retirement. He had many friends there.

He had a deep interest in the process of writing, an occupation he patently enjoyed. After his retirement he attended many courses on creative writing, both in the UK and the USA. He was engaged in a project at the time of his death. In 1988 another deep interest surfaced, which astonished his friends: he took up flying, soon obtaining a pilot's licence and thereafter logging many hours of solo flight.

Over the years he took a great interest in the careers of those who had worked with him. Many kept in touch with him and will testify to his support and help.

Kenneth was a gentle and scholarly man. He was a very reliable and supportive colleague. His erudition and knowledge of the psychiatric literature was hugely impressive and was available to any who cared to ask. Initially, Kenneth could perhaps give the impression of being a little reserved, but beneath this was a capacity for deep and lasting friendship.

He was deeply attached to his family and leaves a son and two daughters and two grandchildren on whom he doted.

CliveTonks

\section{Obituary of Steven Bosa}

Published September 2000

(Psychiatric Bulletin, 24, 356).

Additional comment to the above obituary

During the unsettled years after the Amin regime Steven continued to be the mainstay in the Ugandan mental health services.

While I was external examiner in the early 1980s he asked me to give some of the undergraduate $8.00 \mathrm{a}$. m. lectures. At 7.00a.m., at the guest house on Namirembe Hill, overlooking the town where I was staying, we could hear explosions of grenades and gunfire down in the market area. My first thoughts were that the fourth year did not need a lecture on anxiety from me that morning! However, at 7.30a.m. Steven arrived to take me to the medical school. When I informed him of my concern he cheerfully advised me that we would simply drive round the troubles and I was shamed into doing so.

There then followed a threat by the anti-Government forces that they planned to invade Kampala and kill any persons remaining there. As a consequence most of those who could, left the city. This included hospital staff in the acute mental health unit. My own reaction was to keep a very low profile. Steven's response was to move into the unit armed with several days' food for the in-patients and he himself gave sole supervision to staff and provided all medication, nursing and medical care for the next few days.

This was entirely in character with Steven being a remarkable professional.

\section{Harry Egdell}

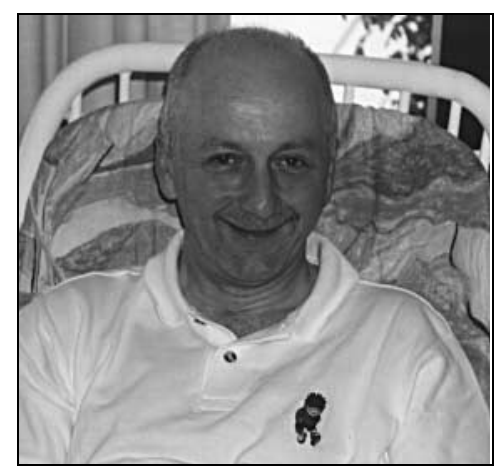

\section{Denis Vernon Carpy}

Formerly Psychoanalyst, Consultant Psychotherapist, Southern General Hospital, Glasgow

Denis Carpy was born on 24 July 1951 and died on 9 June 2000. His early death has robbed British psychoanalyis and Scottish psychiatry of one of its most prominent figures. His contributions as a clinician, supervisor and teacher were widely recognised and his loss is sorely felt.

Denis Carpy was brought up in Rutherglen and educated at Holy Cross High School in Hamilton. He went to Glasgow University in 1968 to study medicine and graduated in 1974. He was elected MRCP in 1977. His early postgraduate posts were in general medicine, but it was always his intention to practise psychiatry and he became a registrar in psychiatry at the Southern General Hospital in 1977. Thereafter, he was a lecturer in psychological medicine at the University of Glasgow before moving to London to specialise in psychoanalysis. He worked initially at the Cassel Hospital before moving to the Tavistock Clinic as a senior registrar in psychotherapy. He completed his psychoanalytic training and became an associate member of the British Psycho-Analytical Society and a consultant psychotherapist at the Tavistock Clinic. Throughout his time in London he remained close to his roots in the West of Scotland and, when the opportunity arose, he returned and became consultant psychotherapist at the
Southern General Hospital in Glasgow in 1990.

After his return to Glasgow he remained active in the British PsychoAnalytical Society. His reputation there had been high and it increased in the years that followed. He was very keen to foster wider links between psychotherapists based in Scotland and the practitioners of the British Psycho-Analytical Society.

Dr Carpy was an inspiring teacher, keenly interested in teaching the effectiveness of psychoanalytic theory in understanding people who present with emotional problems. To further this aim he took on the position of course organiser for the West of Scotland Postgraduate Training Scheme in Psychiatry.

In the field of psychotherapy in Scotland he provided a degree of intellectual leadership that was much admired. He was specialty tutor for psychotherapy in the West of Scotland Postgraduate Training Scheme, a training analyst and secretary of the Psychoanalytic Training Committee of the Scottish Institute of Human Relations, an active member of the Scottish Association of Psychoanalytical Psychotherapists and of the Psychotherapy Section of the Royal College of Psychiatrists. He was elected MRCPsych in 1979, and elected to the Fellowship in 1999.

In his work at the Southern General Hospital, Dr Carpy exhibited a high level of clinical expertise. He was keenly aware of the importance of psychotherapeutic insights to the work of general psychiatry and he worked hard to build links between these two disciplines. His opinions on clinical matters were widely sought by psychotherapy colleagues and general psychiatrists. His pupils and colleagues found his insight helpful, but he was also memorable for the humour and rich language he brought to his work. A paper published in the International Journal of Psychoanalysis on the mutative effect of tolerating the countertransference has been a seminal contribution much quoted in the international psychoanalytic literature.

Despite his heavy professional commitments the most important part of Denis Carpy's life was his marriage and his family. He was happily married to his wife Carol-Anne and their close relationship and mutual support for each other was recognised by all who knew them. Together they established a loving and caring environment in which they raised their two children, Brian and Eleanor.

Dr Carpy's life was cut short, but not before he had made a lasting contribution that will live on in many lives; his family, his friends and colleagues, his patients and his students.

\section{J. Gallagher, M. Malcolm}

